\title{
Gender Bias in the Curriculum: A Reflection from the English Textbook
}

\author{
Jingxuan Rong ${ }^{1, a,{ }^{*}, \dagger}$, Guijia Xue ${ }^{2, \mathrm{~b}, *, \dagger}$, Mihan Zhang ${ }^{3, \mathrm{c},{ }^{*}, \dagger}$, Mengxiao Zhou ${ }^{4, \mathrm{~d},{ }^{*}, \dagger}$ \\ ${ }^{1}$ Ningbo Xiaoshi IB high school, Ningbo, 310000, China \\ ${ }^{2}$ Shanghai Weiyu International School, Shanghai, 200124, China \\ ${ }^{3}$ Shanghai Pinghe School, Shanghai, 200434, China \\ ${ }^{4}$ Xingzhi College, Zhejiang Normal University, Jinhua, Zhejiang, 321100, China \\ ${ }^{*}$ Corresponding author.Email: ${ }^{a} 649234513 @ q q . c o m,{ }^{b} 2968873504 @ q q . c o m,{ }^{c}$ guanghua.ren@gecacademy.cn, ${ }^{d}$ \\ zmx0610@yahoo.com \\ ${ }^{\dagger}$ These authors contributed equally.
}

\begin{abstract}
This paper seeks to explore gender discrimination in the school EFL textbooks. With the awakening of gender equality awareness, gender bias in education has been widely concerned. As a tool in the teaching process, the textbook is one of the essential parts of education, which influences teachers' teaching methods and affects students' ideology. Thus, gender bias contained in the textbook imposes far-reaching and negative influence on students' confidence, learning enthusiasm, future family participation, and employment choice. Also, this paper analyses the representations of gender bias in the textbook from the perspective of visual image and verbal language. Finally, this paper proposes that alleviating the phenomenon of gender bias in textbooks needs the publicity from all walks of life, media dissemination, and financial support for book revision.
\end{abstract}

Keywords: EFL textbook, gender bias, influence, visual image, verbal language

\section{INTRODUCTION}

"Women should act like women." "Women should do what women do." These kinds of voices can usually be heard. It seems like all the women's actions should be exactly fixed on what the public thinks they should be like, instead of what they are inside. Children will become who you say they will become or who you say they are. By labeling girls as uptight, nerdy, princess, bossy, tomboy, or ditzy [1]. Studies have shown that girls are twice as likely as boys to worry that leadership roles will make them seem "bossy" or "aggressive." [1]

However, this circumstance has been reduced in recent years. The word "gender equality" break into people's views. It has been discussed and attracted most people's eyes in recent years. It does not mean that women should be seen as victims and should be compensated by the public or women and men must become the same, which beginners usually misunderstand. On the contrary, it is a word that refers to their rights, responsibilities, and opportunities will not depend on whether they are born male or female [2].
To reach the aim of gender equity and increase people's awareness of gender equality, experts and people concerned have tried many actions to promote and improve [2].

For instance, women's voices should be heard and considered important by the public, so every year, various public speaking is held to encourage more and more women to stand out and show their own opinions and concerns. Therefore, World Conference on Women is set up. It put forward the word "Gender mainstream" [3], focus on women's legal and economic status [4], and other discussed issues of global women's concern and various issues involving women [5]. Furthermore, stopping child marriage and sexual harassment is also a good way to accelerate gender equality, leading to promotions. Public service advertisings are designed to the viewpoint [6]. At the same time, they give women, especially young generations, opportunities to attend schools and have equal rights to have basic educations. Skilled knowledge can push more women who have the ability and willingness to try "non-woman" vocations such as engineers, programmers. They are considered as "men's work" for a long time [7], help them to escape traditional 
vocations related to teachers, nurses and housewives and so reduce the potential discriminations in both their workplaces and their families [6]. This can increase GNI simultaneously because Dollar and Gatti's research found out that a percent increase in the share of females with secondary education raises annual per capita income growth by 0.3 percent [8].

In addition, it should be noticed that considerable progress has been made in increasing access to education, but gender inequality is still appearing during the education process.

Textbooks always play an important role in the classroom discourse. Students spend around 80 to 95 percent of their time in their whole class time on textbooks [9], while another research from this number reaches around 70 to 90 percent [10]. At the same time textbook is one of the major materials helped teachers to do "their instructional decisions" [9]. In addition, every textbook has not only its educational role but also an upbringing. One [11] textbook is sufficient to build initial explicit and implicit values and norms to young generations who do not step into society and start their careers [12].

\section{THE IMPORTANCE OF TEXTBOOK IN CLASSROOM DISCOURSE}

\subsection{The Role of Textbooks in Classrooms}

Textbooks play a very important role in classroom discourse. Teachers use textbooks to prepare lessons, and students use them from previewing, learning, and reviewing. At schools, textbooks can affect students' thoughts and studies in many ways and help teachers create an effective learning situation. For the teachers, a textbook can serve as an inspiration for classroom activities. Teachers prepare lessons based on textbooks, while students see textbooks as a framework or guide. Their opinions and thoughts may easily be influenced. For example, suppose in a textbook, the boy characters raise valuable ideas and the girls often give wrong answers. In that case, the students will believe that boys do better than girls in studies imperceptibly. Or else, if a textbook chooses a lot of passages showing the weakness of women and how strong men are, the gender inequality concept will quietly grow in the students' minds.

Textbooks play a very important role in courses. They are the basis for input learners receive and help the learners to review and practice. Textbooks provide a lot of certain knowledge that the students will follow to learn. This can ensure that students in different classes can receive the same knowledge from the books and have an equal education schedule. If generations and generations use the textbook, its quality is guaranteed. Students can feel safe to choose certain textbooks as their learning materials and improve themselves. Students use textbooks to enhance their learning and work as a memory aid. As a result, we need to choose textbooks and write textbooks with great care.

The textbook helps the teacher to prepare for his/her following courses. Textbooks are so useful that any other tools cannot replace them. The textbook shows the average teacher of English how to present and drill each new point orally before he goes on to reading lesson based on it. Teachers need to create suitable situations for their students, in which the form to be taught used naturally and in such ways that the pupils grasp it [13]. Therefore they'll be needing the textbooks. Education experts often write textbooks. Their work can influence the teaching style and ideas in many ways, for many new teachers are not very sure what to do on stage. Some teachers get inspiration from textbooks, which prevents their classroom from being dull because some are not creative from the beginning. If some concepts about gender discrimination are hidden in the book and the teachers don't pay much attention, then the concepts will be delivered to students.

\subsection{The Use of Textbooks}

Prescribed textbooks have been frequently used in Education to integrate discipline knowledge and support teachers in developing students' learning outcomes [14]. A large Australian study of textbook use in higher education institutions reported that almost all science, Mathematics, Business, and education courses prescribed a textbook as essential for student learning.

Before teaching, contents in textbooks have censored by teachers because gender equality still lacks attention nowadays. Gershuny states that stereotypes limit behavior and understanding and establishes a false impression on people who read them [15]. Stereotypes of masculinity and femininity can be found almost in every textbook used frequently in school lives. The situation has been around us for a long time. Many years ago (maybe still today), most textbooks, dictionaries, and things like that were edited by men. In their work, they used tons of sentences showing women's weakness and normality. This can be shown in research carried out by Hartman and Judd. They found that women rarely play important roles in most cases [16]. They are mostly 'invisible, as their roles in a book will never be noticed. They also counted the sexlinked proper names, titles, or non-generic pronouns and reported in their findings that male references outnumbered female ones. For example, in one of the books that Hartman and Judd examined, the ratio of male to female references was found to be $63 \%$ to $37 \%$ [17]. As housewives and with naïve personalities, they cook and wash clothes to satisfy their husbands. However, the men can do things such as driving new sports cars, earning money to raise the family. These textbooks are always the powerful ones. They make important decisions and have higher family positions. Even the teachers may not realize that they are delivering a message about gender 
discrimination to students because some of them just can't notice sexist contents that have already been implanted into the whole textbook system.

Above all, the influence of textbooks cannot be ignored. It is still important for us to eliminate all the concepts about discrimination and create a healthy and equal study environment for students.

\section{THE INFLUENCE OF GENDER BIAS IN TEXTBOOKS}

Since textbooks are one of the main media for students to learn and play a significant role in students' education, gender bias in textbooks will cause many potential problems.

\subsection{Influence on Students' Value and Gender Identity}

Gender bias in textbooks forms a stereotypical male and female character, thinking model, family role, and career choice, which affect students' gender consciousness, and ultimately affect students' gender roles.

Based on the statistics and analysis of the current PEP Chinese textbooks from primary school to high school, it is found that the traditional female personality traits still dominate the heroines in primary school and junior middle school. They are mainly expressed in the four: "kindness", "consideration", "kindness" and "love for children"[18]. On the contrary, male protagonists are mainly characterized by masculine personality traits, and this trend is strengthened from primary school to senior high school [18]. The traditional male and female personality traits in textbooks will greatly influence students, which is unfavourable to cultivate students' personality traits.

Textbooks even consist of stereotypes on gender thinking models. In Chinese textbooks, a large part of the activities that women participate in is mainly emotional activities, while those that men participate in are more rational [18]. Thus, under the circumstance that Chinese textbooks encourage male students to develop rational thinking and female students to develop emotional thinking. For example, in the Chinese textbooks of primary school, women participate in family activities such as "mother sends birthday gift to daughter", "daughter sends birthday gift to mother", "daughter takes care of sick mother". These examples reveal that the female is better at expressing their emotions and taking care of their family members, which are mainly emotional activities [18]. But men have a variety of activities, such as "dressing small trees", "driving ducks into the circle", "painting", "inventing an inflatable raincoat", "watching the sails in the house", "meditation" and so on, thinking activities are more prominent [18]. The result is that the gender bias in the textbook will limit both males and females, thinking models.

Also, there are great differences between male and female occupations in the current PEP Chinese textbooks. Through the statistics of the occupation of the leading characters in the current PEP Chinese textbooks, it is found that the occupation types of the female characters in primary school, junior middle school, and senior high school are mainly literature, education, and no occupation. There is only one female character who takes science and technology research as an occupation [18]. Compared with women, the professions of male characters are very rich, involving all kinds of professions. Such occupational gender bias exists in textbooks caused occupation stereotypes for students [18]. Because students often look to same-sex figures in textbooks as role models. Therefore, female students may have career stereotypes because textbooks constantly suggest that mathematicians, scientists, and other scientific research professions or careers are male occupations.

The neglect, stereotyping, and distortion of female images in textbooks leads to the absence of female images and makes female roles strained in limited fields. While gender is innate, gender roles are learned. The number of female images in textbooks is small. The limited female character images and character qualities in textbooks will inevitably lead girls to subconsciously ignore the images and qualities of these characters. This makes it more difficult to find female images to arouse their resonance and reduce girls' thinking on their gender images [19]. On the other hand, the lack of excellent female roles in textbook prevents female students from getting the correct role models that female roles should have but also leads them to believe that "girls are never inferior to boys" [20]. According to the research of American scholar Wood, the fact that women are silenced, stereotyped, ignored, and distorted in textbooks will make students believe that the male experience presented in textbooks is correct. Only men can make contributions to society, thus affecting the establishment of female students' gender confidence. Therefore, textbooks that weaken women's actual ability and belittle women's real status conflict with the social and family environment that attaches importance to gender equity, which is not conducive to girls' setting up a correct gender concept and hindering the establishment good gender role [19].

The abundant male images and numerous role models in the textbooks are conducive to male students' realization of gender identity, the establishment of selfconfidence and ambition, and their achievement motivation and choice of career roles. However, the number of male images and male role models in the textbooks is far more than the female ones, which results in gender bias in the textbooks and makes male students the hidden victims of gender bias [19]. On the one hand, it potentially affects the enthusiasm of boys to participate 
in family life in the future. In Chinese textbooks, men work outside, while women spend most of their time taking care of the home. This will make boys think that housework is not men's thing and then resistant to participate in housework consciousness [20]. On the other hand, many stories of male celebrities depicted in the textbooks can help students to follow the example of celebrities and work hard. Still, the differences between individuals, environments, and times are often overlooked by students. This may make the boy extreme, cannot correctly understand themselves, lead to a psychological gap, produce certain psychological problems [19]. These two aspects are not conducive to boys forming a tolerant gender concept.

\subsection{Influence on Students' Future Perspective}

Several studies in China have shown that male and female students' different preferences in choosing subjects are mainly due to gender-biased expectations related to gender differences. Society needs "lady", education should train girls to have "girl-like"; men dominate social technology, and schools have more boys in science and more girls in arts [21]. Also, the lack of female role models and the image of housewives in the textbooks will affect female's learning motivation. The serious lack of female role models in textbooks leaves girls with no role models to imitate and learn from, which is not conducive to motivating girls to think about their future development [19]. Hence gender bias in a textbook will affect students' subject choosing and their learning interests.

The stereotyped gender stereotypes portrayed in textbooks may lead to many students' misunderstanding of gender and their abilities, thus hindering their potential development and affecting their career development. Textbooks overemphasize male images while ignoring female images, which leads to girls not being able to find their gender in the textbooks and believing that they cannot shoulder the same responsibilities as men in many fields [22]. At the same time, the lack of successful female characters and excellent gender role models in textbooks leads to the low status of the female gender in the cognitive world of girls. Therefore, women become more and more self-abased, with a low achievement motivation and less initiative to diversify career choices, giving up fighting for their due social and family status [22]. The emphasis on outstanding male role models in the public sector may also cause them to reject some service industries such as salesmen [21].

\subsection{Influence on the Whole Society}

As the carrier of culture, textbooks provide an invisible way for the dissemination of traditional gender culture. Traditional gender bias penetrates students' ideology through the inheritance of textbooks [23]. Students who have learned the traditional gender bias will enter and then integrate this concept into society with this gender culture and enter the next socialization process. Thus, they may also socialize their children with traditional gender bias [22]. Generation after generation, which causes a "circular effect" of gender bias. Therefore, the gender bias implied in textbooks will be gradually strengthened and continue from generation to generation.

Gender bias in textbooks will also influence the development of education in two aspects.

Firstly, it affects the implementation of educational equity. As the most important educational medium, gender bias in educational books will affect educational fairness and make male and female students lose equal opportunities to receive an education. The male bias in textbooks deprives male and female students of equal opportunities to receive an education [21]. Textbooks do not adequately reflect women and their experiences, contributions, and perspectives, undermining female students' exposure to a wide range of female role models. As a result, some girls can't identify with their own culture in the textbooks, which affects their identity with their own culture [21]. To promote education equity, it is necessary to advocate multicultural education, respect and accept different viewpoints and cultures. The implicit male-centered culture will undoubtedly hinder the realization of educational equity [21].

At the same time, multicultural education, which advocates equality in education, will also be influenced. Since women's identification with their own culture is weakened, and women cannot find the basis to support their own culture in textbooks, the development of female culture itself has been restrained [20]. Textbooks substitute "one" for "two" in gender culture, which not only objectively causes the inequality of gender education but also causes serious obstacles to the development of multicultural education [20].

\section{THE REPRESENTATIONS OF GENDER BIAS IN THE TEXTBOOK}

According to previous studies [23-25], gender bias exists in the textbook, which "not only constrain male (M) and female $(F)$ students' relationships with people of the other gender but could also restrict the conceptualization of their present and future identities [26-29]. Thus, the phenomenon of gender bias in textbooks deserves people's attention. In this study, the textbook's content does "not only refer to verbal text but also visual text because meaning-making is multimodal involving visual, gesture, speech, writing, and sound through which representation occurs." [30][31]. Thus, the following part falls into two aspects: visual image and verbal language. 


\subsection{Visual Image}

Most textbooks adopt visual images as assistant interpretations out of their immediacy and interest. The illustration presents children a resource that expands their world, connects them to society's values, and helps them define who they are [32]. However, visual images are often regarded as decorations [33]. In this way, visual images do not receive due attention. Gender bias contained in them can be overlooked easily, causing potential gender discrimination in students' cognition. To relate different topics, visual images in the textbook often show different scenes, all of which have the possibility of gender discrimination. In 2012, Yasin et al. surveyed Malaysian, aiming to find out the textbook images which illustrate gender stereotypes in five categories, social, institutional, relational, political, and no-action categories. They found that the highest percentage of action that illustrates gender bias distribution is the institutional with $37.69 \%$ (127/337 in number), followed closely by the social action type at $32.64 \%(110 / 337)$, and the third one is the relational categories [25]. According to these data, the visual image part can be divided into three categories: institutional, relational, and social. Based on these data, the visual image part will be specific into three categories, schools, family relations, occupations, which are one-toone correspond to the three aspects mentioned in the above survey.

\subsection{Verbal Language}

In addition to the visual image, verbal language is another essential way for students to receive information. All the beliefs and systems of culture are embedded in its language. The relationship between gender and language is mutual; gender is both reflected and constructed by language [23]. Specifically, gender bias in social consciousness is transmitted to students by the transformation of textbook verbal language. In the Integrative Multi-Semiotic Model (IMM) [33], See Figure 1 , which is a metamodel for the analysis of a page or frame which involves the use of both languages and pictures as semiotic resources [31], the content plane of language is constituted by discourse semantics and lexico-grammar. Therefore, according to this, the analysis of gender bias in verbal language can start from these two aspects.

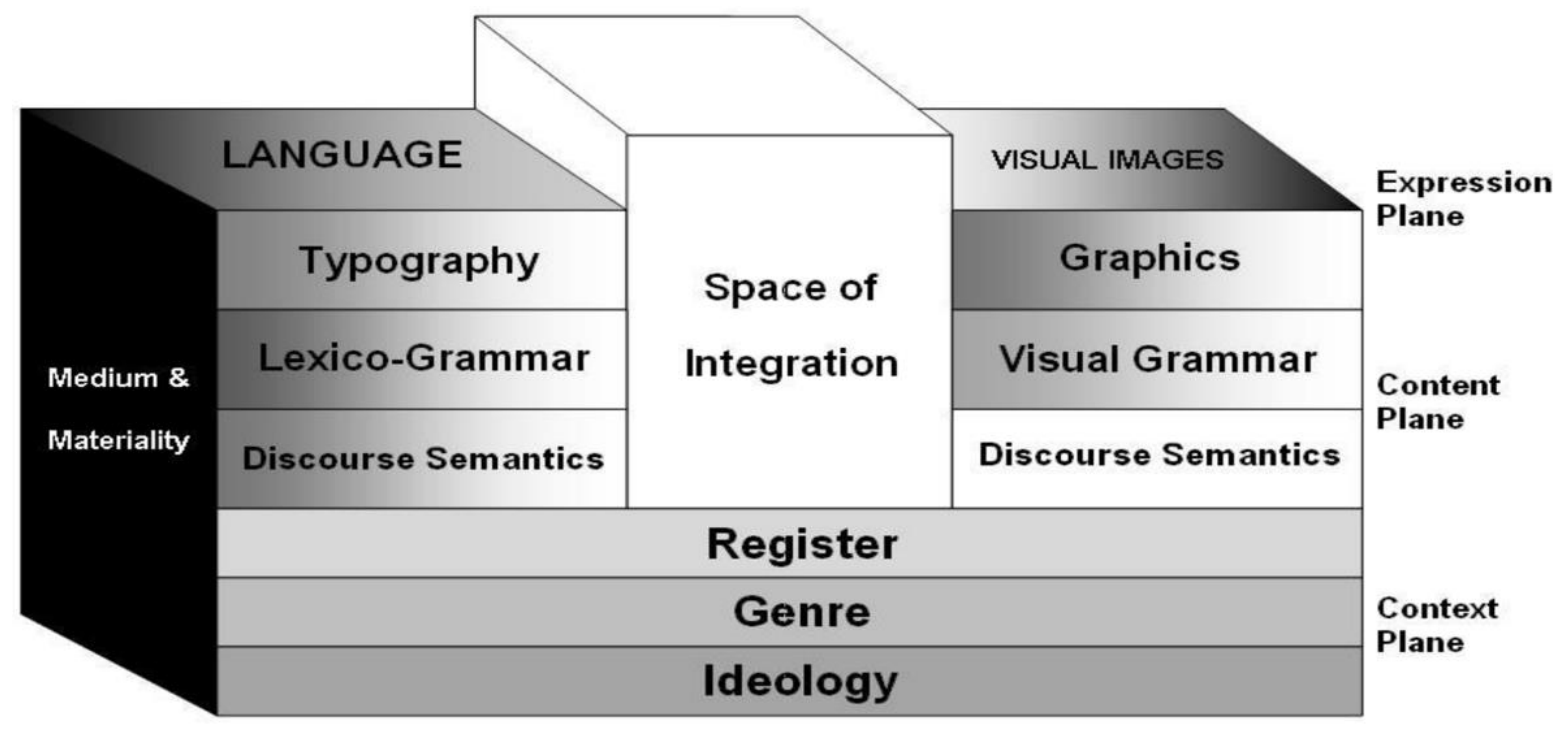

Figure1 Lim’s Integrative Multi-Semiotic Model [33]

\section{CASE STUDY}

\subsection{School}

Images are illustrated most in school classrooms or school playgrounds. Thus, the part of institutional is concentrated in the school. From school activities shown in the textbook, the image illustrates more boys than girls [27]. After analysing eight English textbooks in Guangzhou, China, Xiong et al. found the ratio of male and female illustration is are 2767 illustrations portraying male representing $60.93 \%$, while 1081 illustrations portraying female representing 39.07\% [34] (See Table$1)$.
Table 1. The number and proportion of male and female figures in illustration [34]

\begin{tabular}{llllll}
\hline & Total & Male & Ratio & Female & Ratio \\
\hline 3A & 410 & 225 & $54.88 \%$ & 185 & $42.12 \%$ \\
3B & 305 & 161 & $52.79 \%$ & 141 & $47.21 \%$ \\
4A & 338 & 202 & $59.76 \%$ & 136 & $40.24 \%$ \\
$4 \mathrm{~B}$ & 515 & 320 & $62.14 \%$ & 195 & $37.86 \%$ \\
5A & 271 & 175 & $64.58 \%$ & 96 & $35.42 \%$ \\
5B & 315 & 211 & $66.98 \%$ & 104 & $33.02 \%$ \\
$6 \mathrm{~A}$ & 323 & 202 & $62.54 \%$ & 121 & $37.46 \%$ \\
$6 \mathrm{~B}$ & 290 & 190 & $65.52 \%$ & 100 & $34.48 \%$ \\
total & 2767 & 1686 & $60.93 \%$ & 1081 & $39.07 \%$ \\
\hline
\end{tabular}


As the data are shown in the bar chart below (see Table-2), the proportion of male figures outnumbered female figures in each of the eight textbooks. 3B has the smallest difference in male to female ratio while $5 \mathrm{~B}$ has the largest difference. Though the difference between the ratio of male and female varies from book to book, the overall trend shows that more male figures than female ones in the textbook, which is potential gender discrimination against females.

Table 2. The proportion of male and female figures in illustration [34]

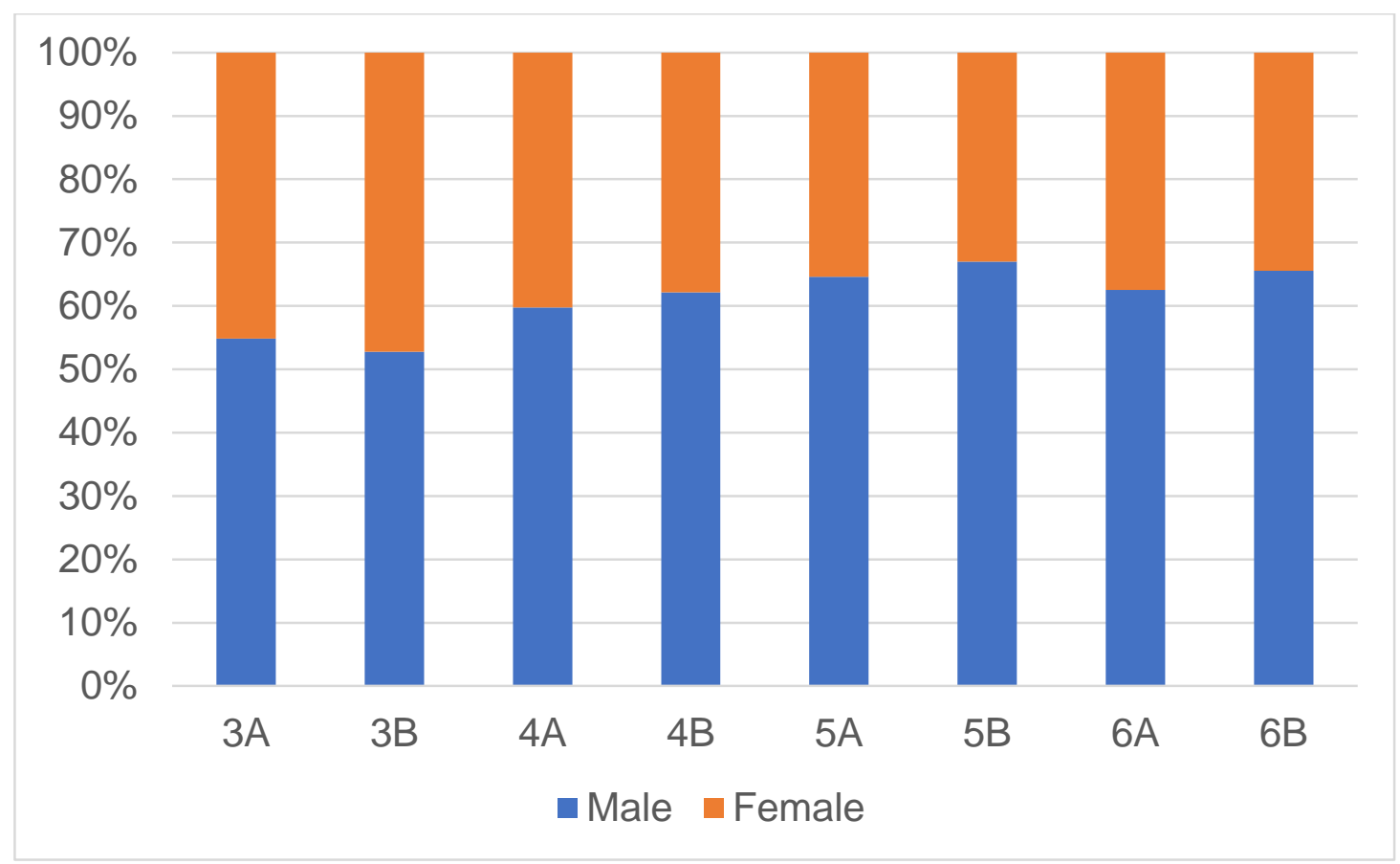

From the perspective of school activity performance, male students are usually dominant, expressive, and active. In an illustration of the Malaysian English textbook (See Figure-3), boys are the ones who prominently sit on the three sides of the table, and they are also depicted as the questioners. At the same time, girls have no opportunity to answer (which can be known from the dialog box). The visual artifacts presented in the textbook impair the function of female students in school activities and positively strengthen male students' image. The kind of visual image representation enhances the gender stereotype in students' cognition.

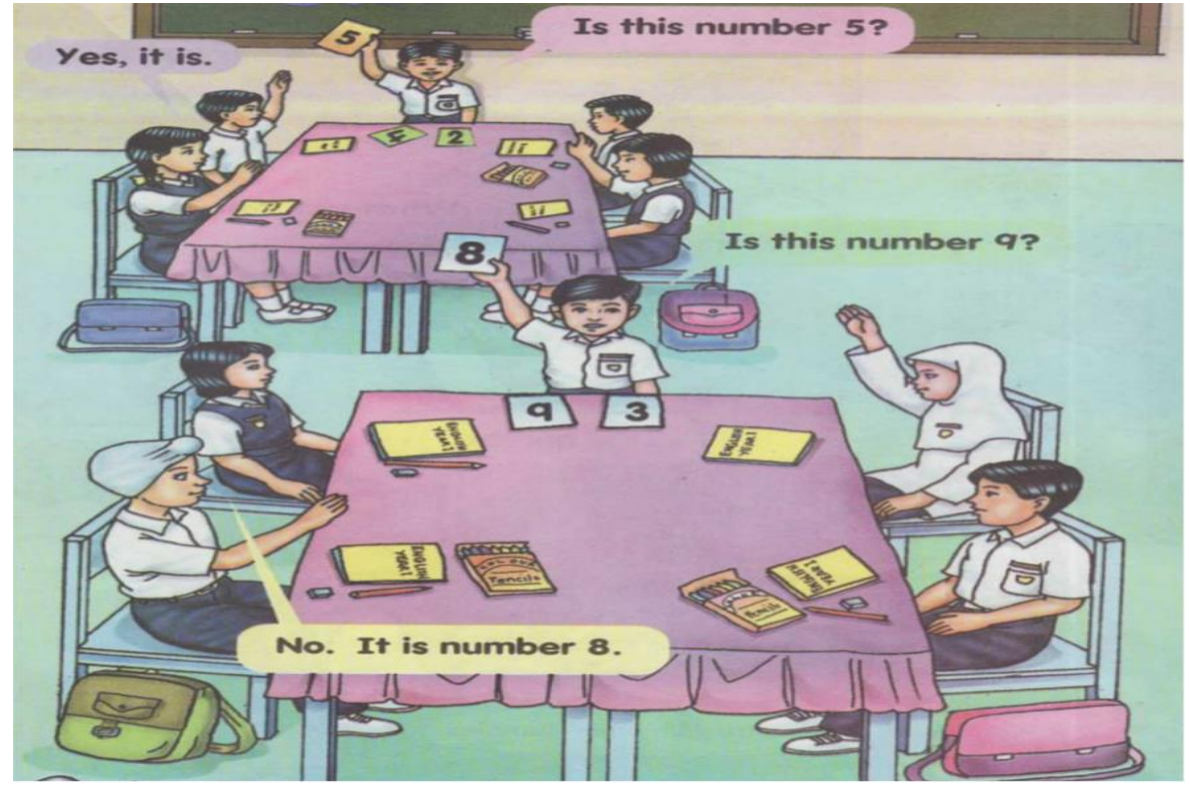

Figure 2 An illustration of Malaysian English Textbook [25] 


\subsection{Family Relation}

In this category, the general statement is focused on the relationship of family activities. In the role of parents, mothers appear holding or feeding or walking babies, but fathers seldom have anything to do with them, except for taking a son to a ball game or sharing outside chores with him [35]. In a study conducted in 2008 in Hongkong, there are more women than men engaging in various kinds of household chores (11 vs. 4 for earlier books, and 7 vs. 2 for recent books) [36]. In 2014, Jabeen et al. mentioned in their study that men are breadwinners whereas women work in household structure taking care of their children [37]. In the English textbook, housework is the main family activity. From the previous research above, females are dominated in household activities, implying that females are more domestic. In figure-4, the father cleans the ceiling while the mother is sweeping the floor with the vacuum cleaner. A mother's job is much easier. This picture depicts the more difficult task, which means the masculine task is dealt with by the father, while the less difficult task that means feminine work is dealt with by the mother, representing the gender liner in the labor division [27].

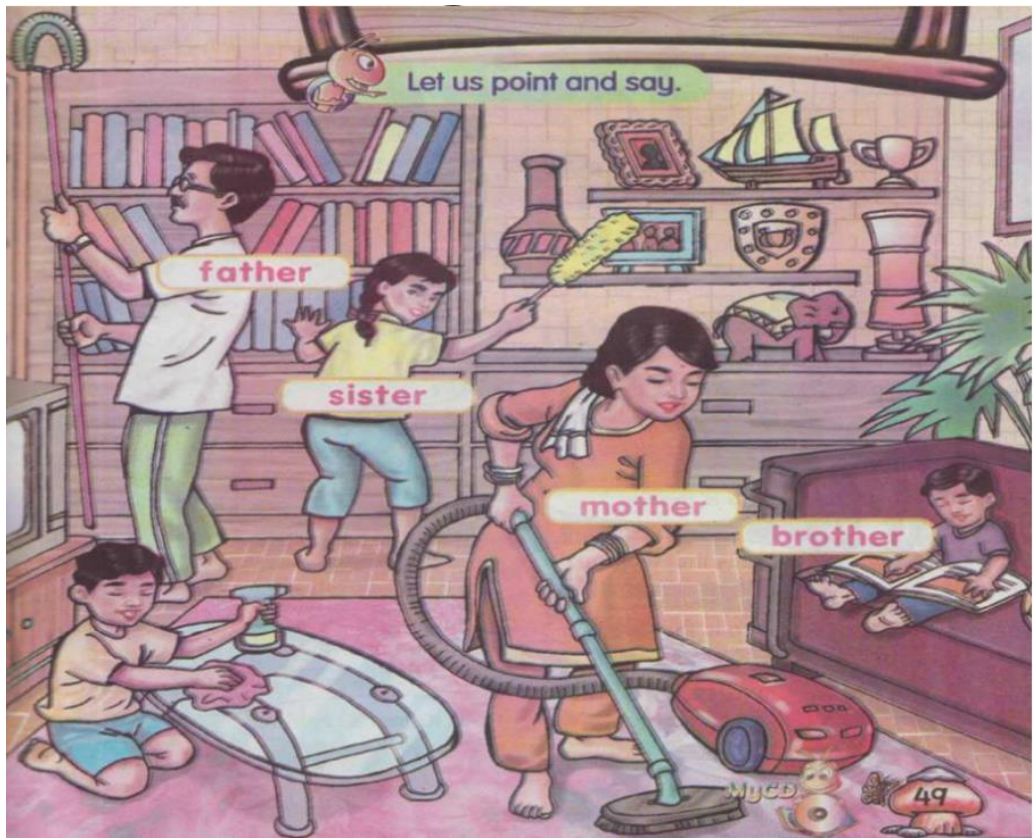

Figure 3 An illustration of Malaysian English Textbook [25]

\subsection{Occupation}

After investigating twenty English language textbooks in Hong Kong, researchers proposed that men occupy a wider range of social roles in the male-monopolized (a type of social role served by man) category in the earlier and recent textbooks: 3036 respectively [36]. The social roles there refer to the different roles people assume in social life [37]. And in the school textbook, social occupation is the most important embodiment of social role. According to a research conducted in Guangdong, China, (see Table-2), males occupy 36 different occupations while the female-only occupies 15 . The difference in occupation variety implies that males are more versatile and have strong capability in different working areas. Additionally, a significantly higher proportion of women worked as clerks or workers in elementary occupations than men. And men are concentrated in occupations that require strong professional skills, such as engineers, programmers. From the distinct characteristics of the job nature, males and females are restricted to some particular image, forming the stereotype of gender in the reader's cognition.
Table 3. Occupational choices for females and males [34]

\begin{tabular}{lll}
\hline & Numbers & Varieties of occupations \\
\hline male 36 & students; drivers; teacher; \\
& farmer; painter; builder; \\
& doctor; poleman; cook; king; \\
& sportsman; factory worker; \\
& writer; fireman; English \\
& lawyer; American footballer; \\
& Chinese teacher; English \\
& teacher; musician; math \\
& teacher; PE teacher; \\
& fisherman; lawyer; scientist; \\
& playwright; artist; musician; \\
& president; inventor; novelist; \\
& runner; painter; filmmaker; \\
& actor; leader; computer \\
& game-maker \\
& astronaut; sportspeople; \\
& vendor
\end{tabular}


female $15 \quad$ student; teacher; salesman; nurse; reporter; driver; farmer; English teacher; music teacher; math teacher; PE teacher; Chinese teacher; train-driver; scientist leader

\subsection{Discourse Semantics}

In the analysis of discourse semantic of the textbook, women's texts are strongly self-reflexive and evaluative, while men were more selfish [38]. There is a dialogue of Indonesian junior high school (See Figure-5). Lisa

expressed her love for Dayu's cat and said, "I can imagine how cute they are." This sentence is quite evaluative if you conduct the in-depth language analysis. If she says, "I will have my cat one day", her character will be much more egocentric because she cares about her thoughts and feelings. There is another case in the Indonesian junior high school textbook in which the male student Beri's attitude is more egocentric, forming a stark contrast to Lisa. In this conversation, Beri expresses his intention that "I will keep my house clean and tidy, too" rather than cater to other's words. The slight difference in the discourse semantics of male and female highlights the personality characteristic of gender, which is also the embodiment of gender stereotypes.

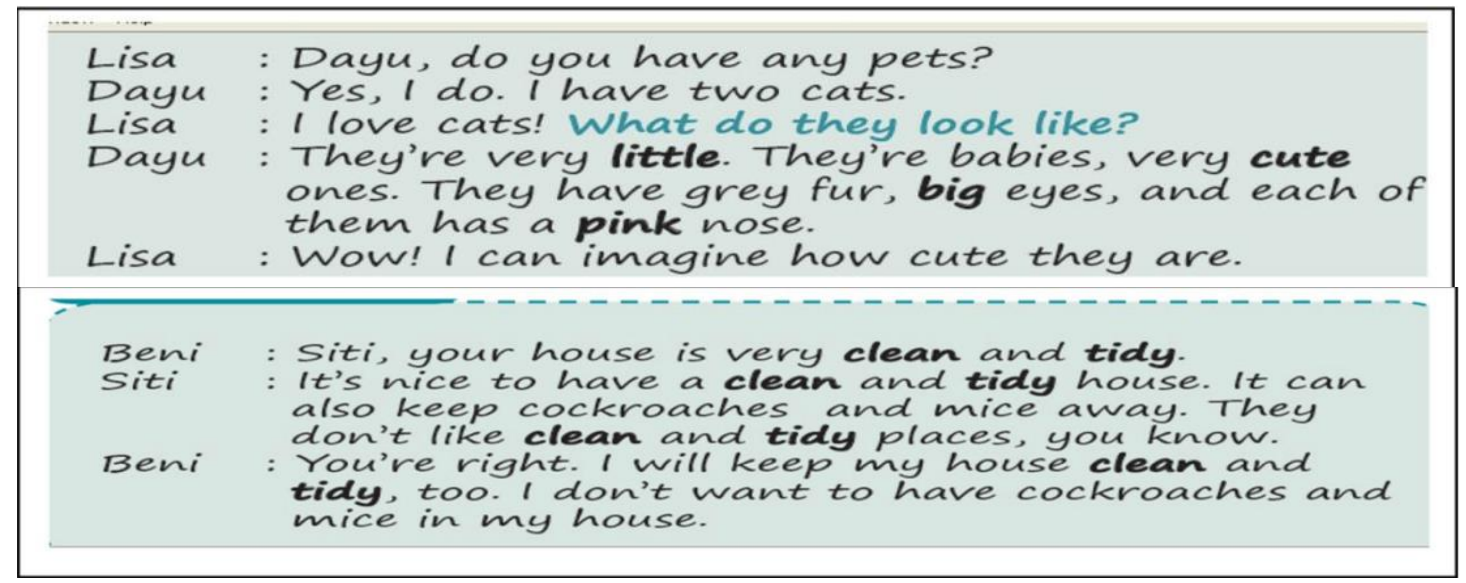

Figure 4 A dialogue in the Indonesian EFL textbook [23]

\subsection{Lexio-grammar}

In the ordering of sex pairs, such as father and mother, brother and sister, all most male term precedes the female term. Although it is a minor point, such automatic ordering reinforces the second-place status of women [17]. Another controversial area of sexism in the English language is male-generic items. By using the male-generic items, such as human, mankind, chairman, woman become invisible. In most cases where words like man, person, etc., and pronouns such as everybody, somebody, etc., are used in EFL textbooks, people hardly conceptualize females when reading such constructions [39]. Solving this problem is difficult because sexist usage is built into our language habits specifically taught to students. But people are still trying it on. Lee and Collins suggested using paired pronoun expressions such as he/she, he or she, him or her, and his or her to avoid malegeneric items [37]. However, it is considered too cumbersome to use in the article or daily communication. Then, another strategy was proposed using "they" as an anaphoric pronoun with a singular, generic, or indefinite antecedent [37].

\section{CONCLUSION}

Textbooks play an important role in education. They help students to review and practice, enhanced their learning and working memories. For teachers, textbooks can provide teachers with knowledge students may have to know, influencing teachers' teaching norms and ideas. If teachers do not pay much attention to gender bias concepts hidden in the article, these contents will potentially be delivered to students.

Textbooks with gender bias can influence students' gender identity, limiting both males and females thinking models. These can lead to a misunderstanding of gender roles and their own abilities, which may affect and hide their potential skill developments and career promotions in the future. From a more macroscopic aspect, for society, if the gender bias in textbooks during their school times cannot eliminate, they may socialize their children with all these negative concepts. Generation after generation, these implied gender bias in textbooks will be generally strengthened and continues, refers to a vicious circle in the end. For the whole education development, educational equity and multicultural education development are restrained. 
In detail, gender inequality is mainly reflected in two aspects, including visual image and verbal language. Textbooks show more males than females attended daily conversations and usually it is males have more dominant, expressive, and active roles. In family, females are more likely to be described as a housewife while males are usually the breadwinners. Females are doing their "traditional" jobs with distinct characteristics of "women's role", leading to gender stereotypes. Another minor point is grammar descriptions. The word "she, sister, females" are usually followed after words to represent men or editors only use male-generic items to describe both men and women.

In this analysis, there are still some limitations. Since textbooks due to Benavot's research, only when huge regime changes those most poor countries will resign textbooks and curricula due to it tend to be very expensive. Therefore, this will make our reference and case study all from very early times, like 1900s, lead to it does not reflect the lasted information or consciousness about gender equity. At the same time, it cannot reflect the present-day realities of the domestic, academic, and worlds, make its usefulness on education reduced. In addition, the image of gender minorities like LGBTQ is rarely mentioned in the textbooks in global period textbooks, especially in Asia. Future research can focus more on how to solve the problem of financial problems on resigning and finding gender bias in textbooks and gender minority groups' defection.

\section{REFERENCES}

[1]. T. Trautner, Dangers of labeling our daughters, MSU Extension, 2016.

[2]. United Nations Sustainable Development, Gender equality and women's empowerment, 2021

[3]. World Women Conference, Mexico City, 1975

[4]. World Women Conference, Denmark, 1985.

[5]. World Women Conference, The Republic of Kenya, 1995.

[6]. UNICEF, Gender Action Plan 2018-2021, Advancing gender equality and the rights of women and girls is essential to realizing the rights of all children,2017

[7]. J. Jacobs,1996. Gender Inequality and Higher Education, 1996

[8]. D. Dollar, R. Gatti, Gender Inequality, Income, and Growth: Are Good Times Good for Women, 1999

[9]. D.M. Sadker, K. Zittleman, Practical strategies for detecting and correcting gender bias in your classroom, 2007.
[10].P. Baldwin, D. Baldwin, The portrayal of women in classroom textbooks, Canadian Social Studies, 26(1992), 110-114.

[11].Pešikan, A, Nastava i razvoj društvenih pojmova kod dece, Zavod za udžbenike i nastavna sredstva, 2003

[12].S. Marinković, M. Erić, The Problem of Value in a Textbook, Social and Behavioral Science 128 (2014) 72R. LeMoyne, An Equity-based Approach to Programming, Operational Guidance Overview in Brief, 2011

[13].A. Sam, Facts About the Importance of Textbook in Teaching, 2015.

[14].W. Fasso, B. A. Knight, C. Knight. Hershey, PA, IGI Global Press, 2014.

[15].H.L. Gershuny, Sexism in Dictionaries and texts: Omissions and commissions., National Council of Teachers of English, Urbana, Illinois, 1977.

[16].P.L. Hartman, E.L. Judd, Sexism and TESOL Materials. TESOL. Quarterly, 12(1978), 383-393.

[17].M. Liliana, Gender Textbook Evaluation, TESL Canada Journal, 2003.

[18].Y. Zhang, Research on Gender Bias in the Current Chinese Textbook of PEP (Master), Qinghai Normal University., 2015.

[19].L. Ge, The sense of gender equality in the schoolbook of Chinese for the elementary school in Shanghai (Master), Shanghai Normal University., 2018.

[20].Y. Chen, Social gender theory-based of gender bias in textbooks for primary and secondary research questions (Master)., Shandong Normal University, 2009.

[21].X. Wang, Comparison Between Chinese Textbooks of Taiwan and Mainland on Gender Consciousness (Master)., Henan University, 2017

[22].H. Zheng, The Research of Gender Role in the Chinese Textbooks for Primary Schools by Xinjiang Education Press (master)., Kashgar University, 2018

[23].N. Aydınoğlu, Gender in English language teaching coursebooks. Social and Behavioral Sciences, 158(2014), 233-239.

[24].S. Ariyanto, A portrait of gender bias in the prescribed Indonesian ELT textbook for junior high school students. Sexuality \& Culture, 22(2018), 1054-1076)

[25].M. S. M. Yasin, B. A. Hamid, Z. Othman, K.A. Bakar, F. Hashim, A. Mohti, A Visual Analysis of a Malaysian English School Textbook: Gender 
Matters. Procedia - Social and Behavioral Sciences, 69(2012), 1871-1880.

[26].J. Gray, The ELT coursebook as cultural artefact: How teachers censor and adapt. ELT Journal, 54(2000), 274-283.

[27].J. F. K. Lee, A hidden curriculum in Japanese EFL textbooks: Gender representation. Linguistics and Education, 27(2014), 39-53.

[28].M. Samadikhah, M. Shahrokhi, A Critical Discourse Analysis of ELT Materials in Gender Representation: A Comparison of "Summit" and "Top Notch." English Language Teaching, 8(2015), 121-133.

[29].R. Goyal, H. Rose, Stilettoed Damsels in Distress: The (un)changing depictions of gender in a business English textbook. Linguistics and Education, 58(2020).

[30].P. Stein, Representation, rights, and resources: Multimodal pedagogies in the language and literacy classroom. Cambridge University Press, UK, 2004

[31].I.K. Damayanti, Gender construction in visual image in textbooks for primary school students, 2014.

[32].A. Sovič, V. Hus, Gender Stereotype Analysis of The Textbooks for. Young Learners. Social and Behavioral Sciences, 186(2015), 495-501.
[33].V. L. Fei, Developing an integrative multi-semiotic model. Multimodal discourse analysis: Systemic functional perspectives, 2004

[34].T. Xiong, J. He, L. Li, The Representation of Gender in a Popular Primary School EFL Textbook Series in China. International Journal of Education and Practice, 5(2017), 79-87.

[35].J.M. Dobson, F. Sedwick, Conversation in English: Points of Departure, Van Nostrand Reinhold, 1975.

[36].J. F. K. Lee, P. Collins, Gender Voices in Hong Kong English Textbooks-Some Past and Current Practices. Sex Roles, 59(2008), 127-137.

[37].S. Jabeen, A. Q. Chaudhary, S. Omar, Gender Discrimination in Curriculum: A Reflection from Punjab Textbook Board. Bulletin of Education and Research, 36(2014), 55-77.

[38].D. Graddol, J Swann, Language, Gender Voices, Communication, and Consciousness. Cambridge, MA: Basil Blackwell, 1989.

[39].K. Porreca, Sexism in current ESL textbooks, TESOL Quarterly, 18(1984), 705-724. 